\title{
“Can We Have More Hand-Drums?” Preschool Children's Musical Play in a Program Exploring Diverse Languages
}

\author{
Aleksandra ACKER | ORCID :0000-0003-4284-6891 \\ Dr; Early Childhood, Music and Creative Practice, RMIT University, \\ PO Box 71, Bundoora, vic 308, Australia \\ Artistic Director of Anja \& Zlatna; Australian Music Councillor for Early \\ Childhood
}

Aleksandra.acker@rmit.edu.au

\begin{abstract}
This paper explores the role of play in a research project that documented and elucidated responses to a culturally diverse music program of five preschool-aged children in a child-care centre in Melbourne, Australia. The study was conducted over a period of nine weeks. The music program was conducted playfully, concentrating not only on the musical features and premeditated pedagogical devices, but on children's contribution to the content and arrangements of the music sessions. The methodology employed in the study was conceptually rooted in the socio-cultural framework. The researcher took into consideration that learning is purported in a social environment and changes in character within a variety of social contexts. The social aspects of play were well-captured in the large number of Learning Stories that were written about and with the children. The Learning Story method of gathering, analysing and planning from data was employed as this socio-cultural approach encompassed contextual factors and celebrated children's active role in the process of learning within and beyond the music program. The analysis of Learning Stories revealed that children's learning is more profound when there are opportunities for play, on their own terms; this consideration is strongly recommended for future research projects.
\end{abstract}

\section{Keywords}

early childhood music - singing - musical play - Learning Stories - languages diversity musical conversation - creative thinking 


\section{Introduction}

This paper explores spontaneous musical play in a research project that aimed to document and elucidate responses to a culturally diverse music program of five preschool-aged children who attended a public child care-centre in Melbourne, Australia. The methodology employed in the study was conceptually rooted in the socio-cultural framework. In line with this perspective, instead of concentrating only on the purely musical features and intentional teaching, the musician/researcher took into consideration that learning is purported in a social environment and changes in character within a variety of social contexts (MacMillan \& Schumacher, 2010). She encouraged children's input into the music-session content and form, involving them in data collection, selection and interpretation. The children were prvided with opportunities for spontaneous play, as they creatively utilised resources from the music sessions.

To contextualise this study, research orientation, Learning Stories approach and the main protagonists - the Children - are described; a succinct overview of the music program and its pedagogical decisions are provided. Learning Story examples are included to illustrate the notion that, like play and learning, formal and spontaneous learning are inseparable. Concluding remarks reflect on the benefits of Learning Stories as a socio-cultural tool, the natural and necessary presence of play in pedagogies of/for young children, and the importance of culturally inclusive music education (Campbell \& Wiggins, 2013).

To provide the background of this research, it is necessary to emphasise that it was founded on the constructivist paradigm. This implies a conception of reality as a multi-layered, interactive, shared social experience interpreted by individuals (MacMillan \& Schumanher, 2010). While the qualitative collection and interpretation of data (staff-interviews, parent questionnaires, audio/video recordings, artefacts, photographic collections, observations, filed notes and reflex-records) provided multiple rich lenses, this paper focuses on the social aspects of spontaneous musical play captured in the large number of Learning Stories. The Learning Story method of gathering, analysing and planning from data was employed as this approach encompassed contextual factors and celebrated children's active role in the process of learning within and beyond the music program. Written about and with the children, Learing Stories allowed for careful tracking of individual and collective development. The analysis of this collection revealed that children's musical growth is enhanced when there are many opportunities for spontaneous play, on their own terms. 
Learning Stories have directly evolved from established methodologies theoretically grounded in socio-cultural theory. Originating in New Zealand, they are now widely used in Australia and other countries (Nyland \& Acker, 2012). They can be short pieces, or several learning episodes linked together which will tell what children 'can do' rather than what they 'cannot do' because children learn most effectively when they feel positive about themselves (Lee \& Carr, 2012). Learning Stories display one or more of the five target domains of learning disposition (Carr, 2001): taking an interest, being involved, persisting with difficulty or uncertainty, expressing an idea or a feeling, and taking responsibility or taking another point of view. They can be used with other teachers, family members and children as a site for interesting and deeper conversations. Parents, too, may be involved in writing Learning Stories and interviews and dialogues from children may be included. In short, as a socio-cultural method, Learning Stories capture the context of the learning environment, describing actions, and making children's interests, feelings, interpretations and social interactions and relationships visible. The visual elements (images, drawings, etc.) which often complement the narratives make Learning Stories an effective, aesthetically appealing, and easily assessible pedagogical, communicative and research tool. The Children

This section is intended to help the reader gain some understanding of the children's demeanours and interests prior to the music program.

Claire was described as an articulate child, who relished talking about her art work, retelling stories about events that took place at either home or at kinder. Her inseparable close friend was a soft dog-toy, "Dugi". Claire often led in play situations. The children usually respond to this and when they did not, Claire, in the words of her teacher, "would stamp her feet while leaving angrily". Claire had been exposed to a variety of songs, including some Italian, learnt through "Playschool". Her favourites were: "Row, row, row your boat", "Yo-ho little fishy", and "Fa-la-la-la bambino". Her family endorsed exploring cultural diversity with young children: "It enriches their [the children's] understanding of the world; they learn about tolerance of people who may seem different to themselves."

Thuan came from a Vietnamese family and had just started learning English. His kinder teacher described him as an inquisitive child, always trying out things, experimenting with objects, finding out different ways to use them. He liked gardening. His parents thought this would "lead him to respect and get to know other people." They felt it was important to know "this [meaning the 
Vietnamese] culture" to interact with their "family, relatives and other Vietnamese people". When talking about singing, they saw it as a "joyful experience one can share with others", offering "many educational things". They sang "educational" and folk songs to Thuan in both English and Vietnamese.

Elan was described as a kind, friendly and creative child who loved to sing and perform. She often sang to other children and to her family, incorporating gestures or other material. Elan's mother's attitude towards diversity was unconditionally positive:

I'm very proud of Australia's multiculturalism and believe it is the best way to live. I love living in Footscray where my children feel it is normal to be surrounded by people from different countries, cultural and language backgrounds...I think my children should feel comfortable with and embrace diversity rather than fear or distrust it, because no man, woman or child is an island.

The most popular songs with Elan's family were 'Topi Saya Bundar' [translated: "My Hat is Round"], an Indonesian children's song. Elan's father lived in Indonesia.

Quentin was described as an outspoken child, with interests in books and discussions about topics such as sea creatures, magnets, or robots. Quentin's mother stated that "singing helps with emotional expression and improves one's spirits and enables sharing of cultural concepts". Accordingly, she wanted her children to enjoy a wide range of musical genres. At home, Quentin had been exposed to contemporary, folk and nursery rhymes. She wanted her Quentin to "mix and match as much as possible with children from other cultures due to the rich demographic structure of Australia and a highly globalised world".

Luke was described as an energetic, physically active child who enjoyed dancing. Like the others, his family embraced multicultural demographic of Australia. They considered singing an important part of the children's development, allowing self-expression "in a funny, lively way" and mentioned that Luke often communicated through singing: for example, he'd sing short phrases like, "Let's go to the park" or "Pass the ball, pass the ball, pass the ball." The songs they shared at home were typically nursery rhymes although the favourites were his father's made-up songs.

The educational setting has a significant influence on children's learning and development, and its philosophy is to some extent reflected in the resources 
present in the centre, in the selection of staff and the profile of children. The early childhood centre for this research was purposefully selected as the importance of diversity and equity that was reflected in the centre's philosophy reinforced the study's focus on culturally diverse materials and songs. The staff and families of the participating children particularly appreciated the notion of children as active learners and partakers in decision making processes.

The central music activity in this project was singing, plausibly the type of music with the strongest cultural associations. Songs carry multiple messages (semantic, emotional, historical, etc.) and are behaviourally complex for the performer as they often entail gesticulating or dance elements (for example Chinese opera). For young children, singing provides an enjoyable way to become acquainted with their background's cultural heritage or with tales and melodies of other cultures (Campbell \& Wiggins, 2013). Due to songs' reliance on lyrics, they also provide a way of familiarising children with words of other languages (Acker \& Nyland, 2017). In this study Italian, Serbian, Mandarin, Ghanaian, Japanese and English were shared. Some of the songs were presented in English and one other language, while other songs were only presented in a language other than English. Because of carefully selected materials and playful nature of the music sessions, a seemingly complex song repertoire became quite popular with the children as they sang and play with the songs beyond the music sessions.

The context within which children would use their singing ability differed considerably among the five. Claire, while reluctant to sing during the group sessions, was frequently accompanying her 'free play' with songs - often the ones introduced during the session. Luke, Quentin, Thuan, and Elan, on the other hand used singing as a form of communication. Luke especially engaged in 'singing conversations', whereas Elan, Quentin and Thuan preferred to perform songs for willing (and occasionally unwilling) listeners. The children were regularly observed experimenting with different properties of the songs, in their spontaneous play, at child care or in family context. This was not a surprise as young children tend to enjoy spontaneous singing, unstructured pitch and rhythm play, and free, improvisatory movement; they begin to notice the style of music and, since they are very much fans of imaginative play, respond to music creatively making up their own songs, playing their own 'accompaniment' (Young, 2018).

The songs were introduced without accompaniment, as it is generally easier for children to match a melody with a human voice than one played on an instrument. When the songs were repeated at a later stage or during other sessions, however, there was sometimes instrumental accompaniment. In addition to singing, the children were given opportunities to move, dance, play games and freely explore self-selected materials. 
In some of the sessions, instruments were used to enhance the learning experience and immersion. These included a guitar and a variety of percussion instruments, such as tambourines. Some songs were enhanced with puppets or books. This served the purpose of addressing the child's individual learning preference, which is an essential precondition for successful learning (Carr, 2001). While these props only occasionally conveyed the meaning of the songs, they helped the children link the songs to a visual anchor or to further stir their interest in their spontaneous musical play. Other resources that were used in the sessions or spontaneous play comprised drawing, painting and writing material, note blocks and photo albums, which contained pictures of earlier sessions. These resources were provided by the researcher and perceived as "special things" by the children who utilised them in their musical play.

Most scholars would agree that it is through play that much of children's early learning is achieved. Governed by their natural curiosity, a sense of wonder and an ambition to explore their world, children show a substantial creative capacity to live in and through their playing. Play enables them to further explore the known and to discover and investigate the unknown. Play is a creative act (Hendricks, 2011) and is a medium through which children may perform above their present level of understanding or intuitively seek meaning by theorising about experience and previous social interactions (Vygotsky, 1978). When it comes to musical play, as with other forms of play, the activities are enjoyable and fulfilling if they are intrinsically motivated and controlled by the players; vocalising, movement, improvising with instruments, etc. are initiated of their own accord and they may choose to participate in them with others voluntarily. They are free of externally imposed rules but may involve rules coconstructed by the children who are playing (Young, 2018). Children's musical play is multimodal - it merges movement with singing, making sounds with objects and instruments. It is visually, kinaesthetically, and aurally active, and as Marsh (2008) puts it, is child-centred, child-structured, child-motivated, and child-run. Young children's musical play is often a social encounter: sharing ideas, synchronizing rhythmic movements with others and replicating melodic gestures (Niland, 2009).

\section{Learning Story Examples}

The condensed examples below illustrate how 'free time' made the group music experiences more meaningful as children could extend their musical play and learning after each music session. 


\subsection{Learning Story: “Oh, man, you are writing Italian!”}

Last time, we sang "There was an old lady' in English but I also introduced Italian for the main characters of the narrative. Before I left the centre, the children requested we do it again, so today, we revisited the song. Perhaps the puppets, as well as the humorous, repetitive and accumulative features of the poem, were rather appealing. The children were visibly pleased to see the "old lady" again as they happily choose their character (puppet). I led the song and Claire - softly but in time - joined in with the repetitive slogan, "perhaps she'll die". Elan was singing all the phrases in English, but she also substituted three Italian words (ragno, vacca, cavallo). Thuan kept with the beat, rhythmically nodding and smiling throughout the song, especially giggling at the end, when the old lady "died".

Quentin confidently and rhythmically chanted "perhaps she'll die" and at the end remarked on Elan's Italian: “My mum is Italian, but I can't remember these Italian words. I want to listen to the story, again". Others agreed, so we revisited the story, and the children decided to swap their puppets around, chuckling when their character was "swallowed". This time, they participated in a similar manner as in the first round, but Elan stuck to English. Claire

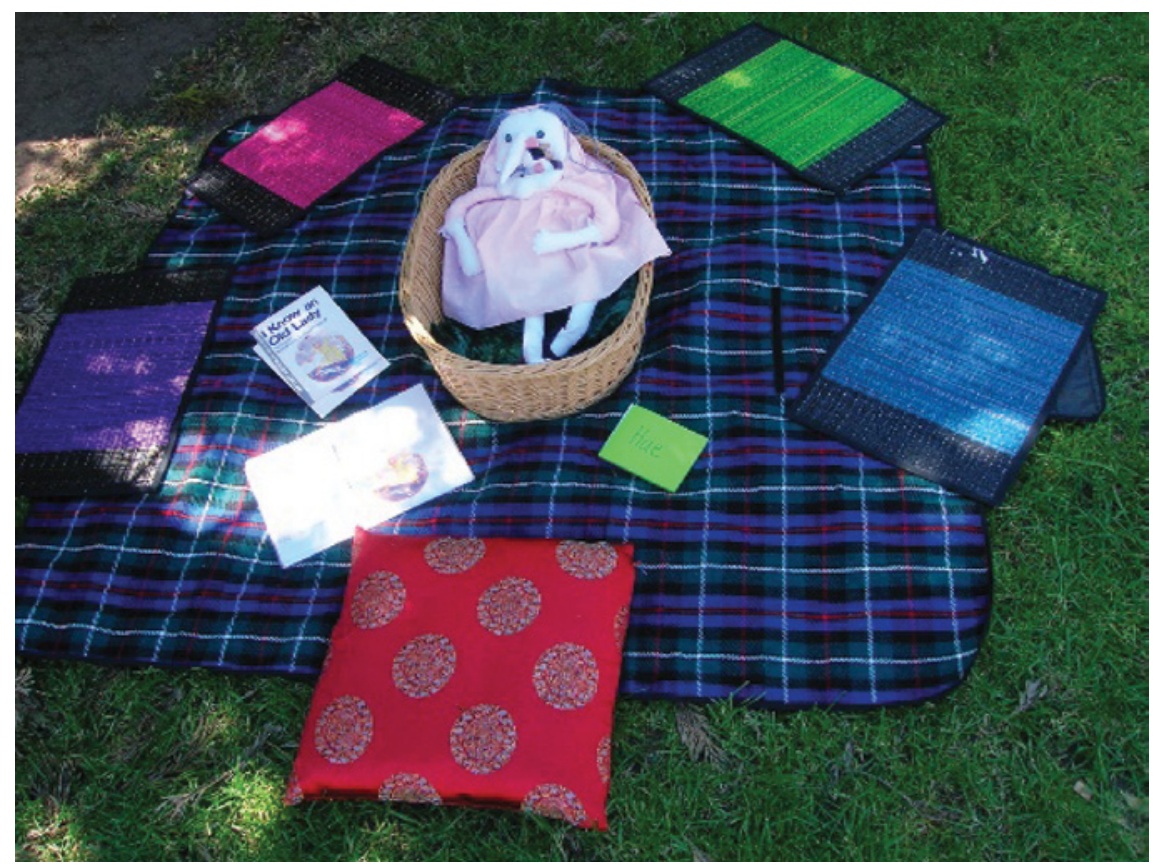

FIGURE 1 Setting the scene 
suggested we leave the "old lady" under the tree, to "have some rest" and "go to play special things".

\subsubsection{Post-Session Play}

As always, after the formal part of the session the children were playing with the resources, on their own terms. Amongst different resources, Claire and Elan were very pleased to find some drawing material. Claire insisted we set up the sketch table. She remarked on the little notebooks: "These are cool." While making marks in her notebook, she mentioned that she saw her dad write in his notebook; "it's a schedule book", she specified.

The other three children sat at the table, each doing a different activity. Thuan and Quentin seemed amused with the variety of colours; Quentin opened each texter, had a smell, passed them on to Thuan who re-lined them up in the pencil case. Elan smiled at Thuan and requested: "Red, please". He pulled the texter out, smiling discreetly, and handed it to her. Elan grinned back and started to copy the flash cards containing the words in Italian. "I am gonna show the words to my mum and Ari" (her sister), she said. "Oh, man, you are writing Italian?!" exclaimed Quentin, curiously looking at Elan's work. Elan confirmed, nodding 'yes'. Quentin looked at Thuan and unexpectedly proposed, "Let's go!" pointing towards the sand pit. Thuan hurriedly placed the pencil case in between the girls and readily hopped off the chair, following Quentin.

"Do you think they would know what the cards say", Claire asked Elan. "No, but I'll tell them...It's the fly and the spider and the bird and the cat and.... and...and the dog and the cow and the horse!" she explained knowingly. "Hm... which one are you writing now?" asked Claire, again. "I think I am doing a fly". "You are right - it is the fly," Claire confirmed. "My mum and dad can read it and we'll teach Ari together," Elan concluded, contented. Claire added, "You need to ask Aleks to show your mum and dad how to read it...and Aleks, we have to do the song again, next time, Luke is away today! Come on Elan, do the song again, I'll wake up the old lady!" Elan smiled and said, "OK, can you bring

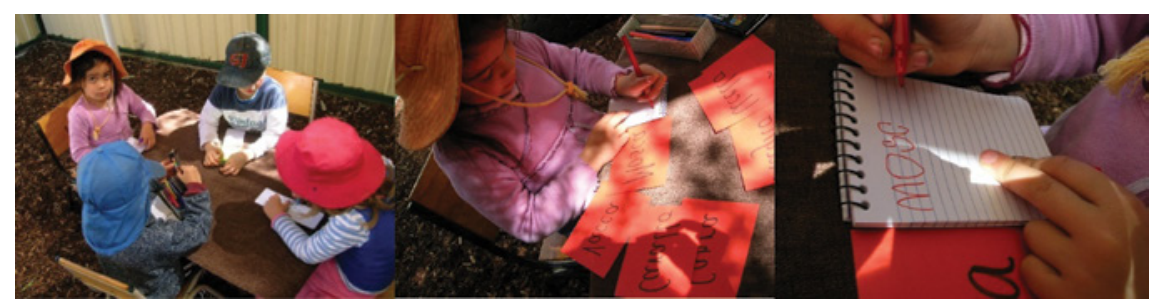

FIGURE 2 Children extending their play with materials from music session 
her over?" Claire brought the puppet over and decided to take out all the miniature puppets. She then brought a pot from the sand pit and placed them in, so as to disguise their presence. Elan sang the entire song, while Claire, confidently and progressively louder, replied singing "perhaps she'll die", sequentially placing the prospective character-puppets that the lady swallowed - fly, spider, bird, cat, dog, cow and horse - into the lady's mouth. When finished with the song, the girls asked Aleks (the musician) to match the words in Italian with the little puppets. Elan took a photo of this and said "we should give them to parents and friends to learn Italian."

\subsubsection{What Learning was Visible?}

The children have been showing an ongoing interest in this story-song. Claire and Elan are encompassing it into their spontaneous play. Because they were familiar with the content of the song and with the idea diverse languages, they are accustomed to this - they acted quite naturally and were more confident, taking it to the next, more intricate level. Elan is a tuneful singer: she maintained the same key throughout the song. Clare, Thuan and Quentin kept a steady beat. The children understand the power of literacy (written language) as a communicative tool and are displaying a sense of ownership and pride as they wanted to keep the notebooks, to share their learning with families and peers. Quentin, once again, shows enjoyment in the story and the puppets and is recognising the challenges that come with learning a new language: he distinguishes that different languages might have different symbols and pronunciation; he seems a little frustrated with this challenge and is openly communicating his frame of mind. Thuan's English (receptive and expressive) is improving and he has becoming more confident to state verbally the words in front of others. He shows responsibility for others' learning, as he kindly placed the writing/drawing utensils for his peers to use; his friendly manner towards others is evident and appreciated and reciprocated by the children. Claire continues to be curious and somewhat inquisitive about other people's mother tongues; she realises that Thuan understands some English and that slower and clear speech might enhance his comprehension.

\subsection{Learning Story: “Can We Have More Hand-Drums?"}

Claire's mother reported that Claire told her about a new, Mandarin song we'd explored - she said that Claire could not remember much, but she did mention some lovely dolls that her mates and Dugi played with. Claire explained to mum, “I don't know the Chinese language, but I know Italian, do you wanna 
write it down?" Claire's mother stated she wrote the following phonetically, as accurately as she could:

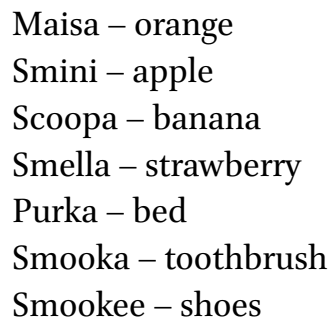

This was really "fascinating and exciting", thought Claire's mother, especially since Claire was "still not able to write her own name".

Later, in the music session, we used percussive instruments that captured the children's interest as we sang a Ghanaian song, 'Umma lella'. We had a small group, but a rather productive one.

The children enjoyed revisiting the song, accompanied by djembe. They were even more keen to explore the sounds and design of the other percussive instruments. They requested we sing the song and play the instruments. The second round of singing was better accompanied by the percussion, so we finished the session on a positive note.

\subsubsection{Post-Session Play}

Thuan and Elan had a lovely musical conversation. During this time, however, Claire was more of a spectator; she watched intensely how 'the music conversation' was created and was excitedly cuddling and squeezing her 'Dugi'.

Soon after, Claire was eager to try out several instruments and managed to hold a few in her hands but realised it would be more effective to make a selection. "I like this one - it feels nice to hold" she described the clapping sticks; "It's better than the hand". "Here, Thuan", she offered, "Try the eggs". Claire suggested they bring a few wooden blocks, Thuan helped her with this and they further explored sound possibilities, incorporating the blocks, producing new sounds. They were being rhythmically playful, creating music together.

Elan led the 'Umma Lella', and the trio accompanied the song. "One more time", Elan said, and the trio repeated the tune, this time in a more musical manner. 


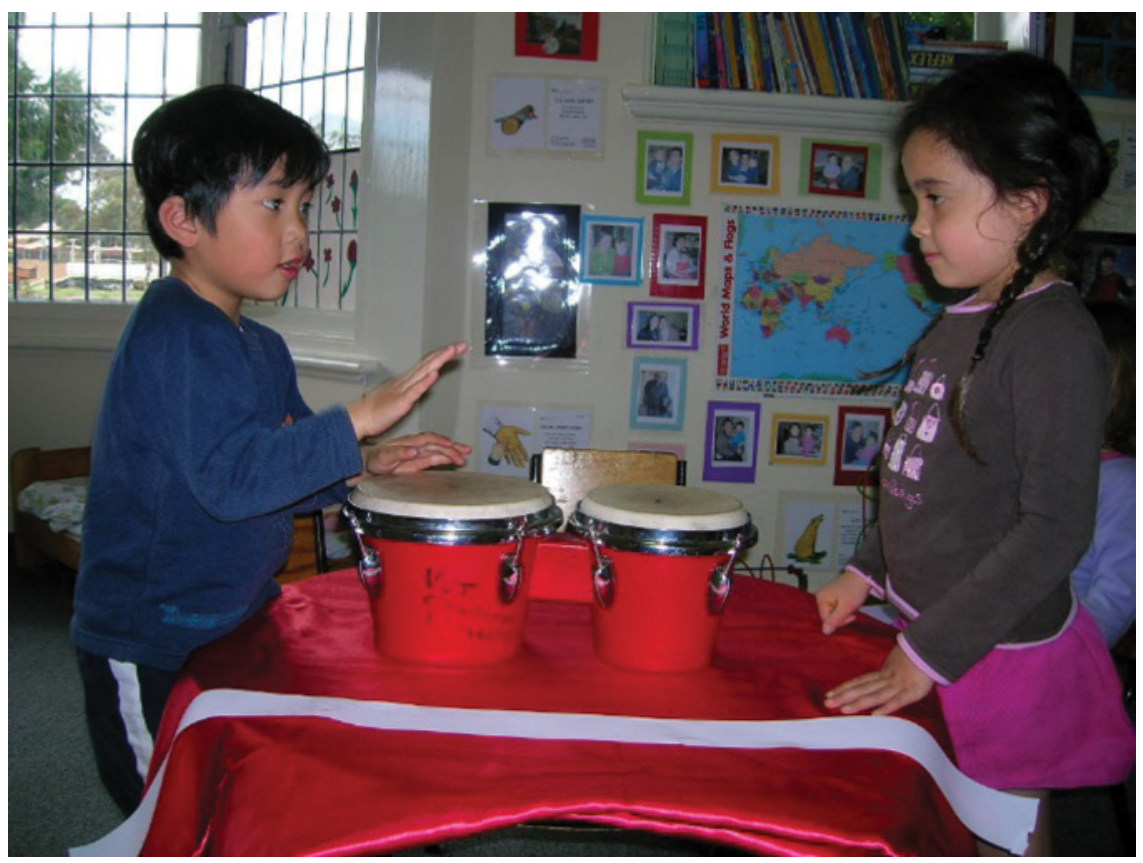

FIGURE 3 Musical conversation

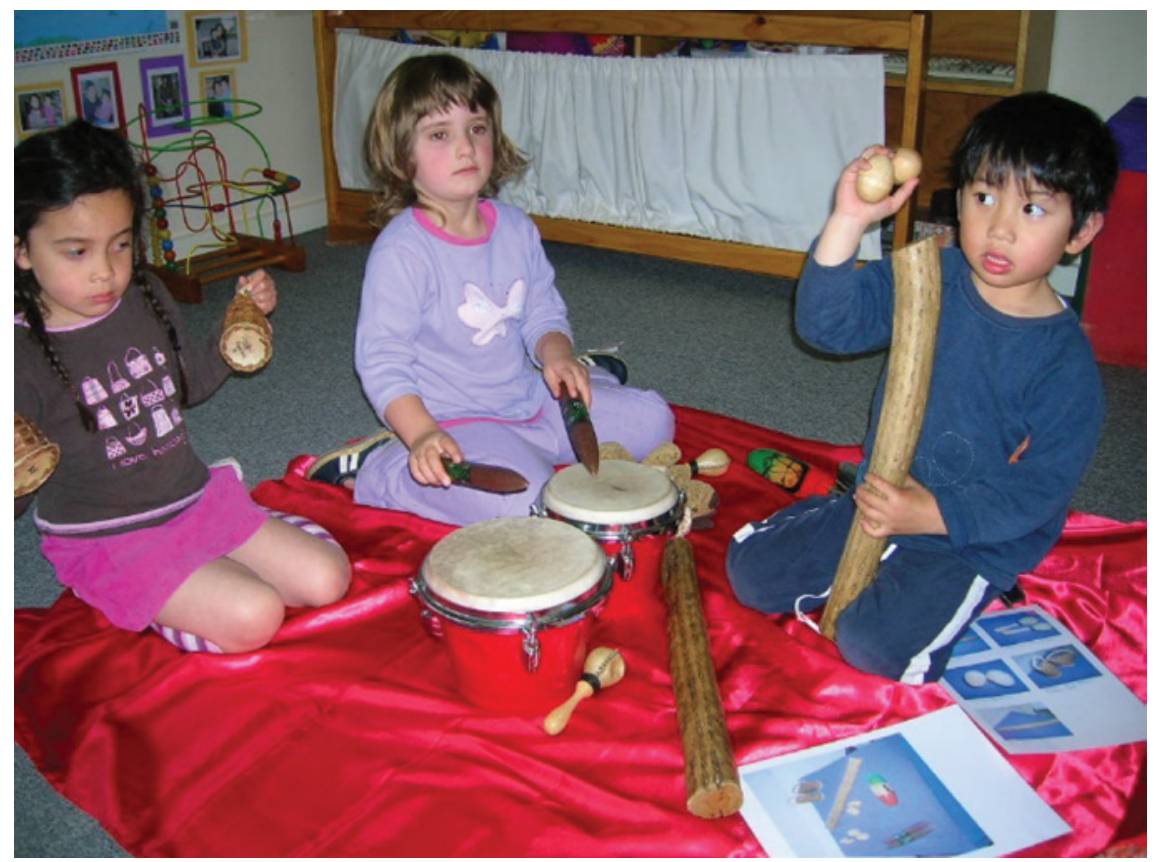

FIGURE 4 Musical play 
Before the musician left, Claire requested: "Can we have more hand-drums... next time?" The musician remembered that she had brought more instruments, so she went to her car and brought another djembe. Claire took one of them, placed her Dugi (toy-dog) on top of it and started to chant in the manner of a counting game. It was hard to transcribe the exact sounds, but the one she repeated four times was definitely "smookee".

She then placed Dugi across the table and had a pretend musical conversation with him, just like Thuan and Elan's; however, she was again, chanting. This time, she made a pause between the words, probably to allow time for Dugi's responses.

The musician was intrigued with Claire's piece, and asked her about it. Claire explained, "It was a morning song," and recited: "Purka, Purka, Smooka, Smooka, Scoopa, Scoopa, Smookee, Smookee, Smookee, Smookee.” The musician realised the sounds were from Claire's list: bed, tooth brush, banana, shoes. Claire insisted: "Make sure you write it down properly."

\subsubsection{What Learning Was Visible?}

The provision of instruments proved effective. The children's fondness for musical instruments and sound making was apparent. As anticipated, the children made use of this additional opportunity to produce sounds and improvise rhythmic patterns. While their efforts were initially purely experimental, some practice gradually transformed their explorations into more musical outcomes on the second attempt to accompany the song. It is difficult to judge to what extent the use of instruments facilitated their earning of the song, but it certainly made their exploration more enjoyable.

Claire's and Thuan's experimenting with the wooden boxes, when trying to create different sound patterns, was fruitful. The sounds they produced varied in pitch, volume, speed and the length of tone.

Claire's humorous socio-dramatic chant is a playful practice and an extension of the language she has been inventing.

All children are showing responsibility and regard for one another. For instance, Claire sought more instruments so that all would have one each. This kind of camaraderie from Claire was not observed at the beginning of the music program.

It is clear that children's learning and means of playing are visible and evident in the Learning Stories. Very soon into the music project, the children became aware of the 'Learning Stories' and the use of photographs. Arguably, they were intrigued by the documentation of the music sessions presented in a Learning Story Album. Elan took the initiative and contributed by taking her own photographs. Every now and then, Claire, who was quite perceptive, 
would ask the musician to "make sure" that what they thought was important information was written down, or captured in a photograph. She also frequently insisted that the musician ought to include all the relevant details about her best friend Dugi. When asked, Thuan would say yes or no to a prospective photo, while Quentin and Luke happily let others decide which snapshots to include; however, they enjoyed going over the sessions, recalling events and remarking on details.

In this project, many of the Learning Stories began with a primary focus on 'taking an interest' and 'communication' domains. However, two processes integrated the five domains of learning disposition: overlapping and sequencing (Carr, 2001) were evident. Overlapping is the process in which related domains work together. Interest and involvement occur at the same time (although one can have an interest without involvement). Often, creative problem solving is a common factor in both involvement and tackling the difficulty. For example, Elan's interest in music and capability to sing in different languages could be associated with her self-confidence and positive attitude towards challenging tasks (persisting with difficulty). Having the motivation to undertake and persist with difficulty enabled her to express her ideas or feelings often. Thuan's sense of belonging and accountability raised his interest and sense of accomplishment.

In contrast to overlapping, the term sequencing refers to the integration of domains of learning disposition into a string of actions. As an example, Claire's negotiations were an accumulation of attention, awareness, engagement, perseverance, speaking out her ideas, and considering the viewpoint of others. The children's involvement in the program followed their interest for the new learning experiences. This led them to persevering with learning new repertoire. They responded to the encouragement and the invitation to freely express ideas and feelings and, finally, they were able to take responsibility and become aware of others' point of view.

As expected, children's play was strongly associated with music when the musician was present. The children indicated a sense of accomplishment as they modelled instrument use for each other, sang, dance, moved and played individually and collaboratively. They became confident to use materials and request favourite items and interests be brought back. Their tastes ranged from exploring sound, to colour and shape, books, dolls, photographs, pictures, dress-ups and even how objects were displayed. The musical eggs were frequently arranged and re-arranged suggesting their sensual shape, smooth texture, colours and a pleasant sound that could be loud enough, but not raucous, were almost universally popular. 
The constraints imposed by space, the levels of acceptable noise, what might be used to produce a sound, and availability of others with whom to make music, all influence the ways in which children will play musically (Young, 2018). In this study, such constrictions were evaded by a stimulating, permissive environment which reinforced the possibilities for children's musical play during and after the sessions. Small group experience allowed the musician to guide the children, individually or collectively, through the musical journey in a gentle, playful and methodical manner; she was present and available to interact, assist and observe responses, needs, interests and challenges these children faced when encountering unknown languages and musical concepts and resources.

When the musician was absent from the centre, the children's play sometimes took on more wide-ranging courses. For instance, there were occasions where the children would bring other play objects (e.g. Thuan brought cakes from his family bakery in the form of playdough) into the play area, transforming the music as it became a part of the wider play arena. At other times, children were observed cooking in the kitchen, using drums as "stoves" and musical eggs as "breakfast". This kind of transformation was a valued aspect of this music project and an opportunity for children to continue to extend or decontextualize items, activities and events from the music sessions. Approaching the same musical experiences across the planned and spontaneous play environments had a potential to strengthen both. Certainly, the children's levels of trust, confidence and collaboration were astonishing at times. Their attempt to look after the music resources and their concern about looking after the instruments suggested a sense of proprietorship. The fact that other children in the kinder room also became familiar with the music-project-songs was a testimony to Claire's, Thuan's, Elan's, Quentin's and Luke's ability to transmit their musical knowledge through languages of play. For example, the kindergarten teacher reported that "Elan taught us 'Giro, giro, tondo' and that children love playing it, especially outdoors...it is a lovely song...easily linked to 'Ring-a Ring-a Rosie"

Other socio-cultural outcomes pertinent to the children as a group concern the group dynamics and the attitude towards others, diverse cultures and languages. During the course of the program the children started forming new relationships and friendships thereby changing the existing group dynamics (see Figure 5). Initially, they would mix by gender or interest; however, as the program progressed, the roles became more open, inclusive and less predictable.

Building and experiencing successful relationships with others greatly enhances children's learning (Rogoff, 2003). The relationships that were formed 


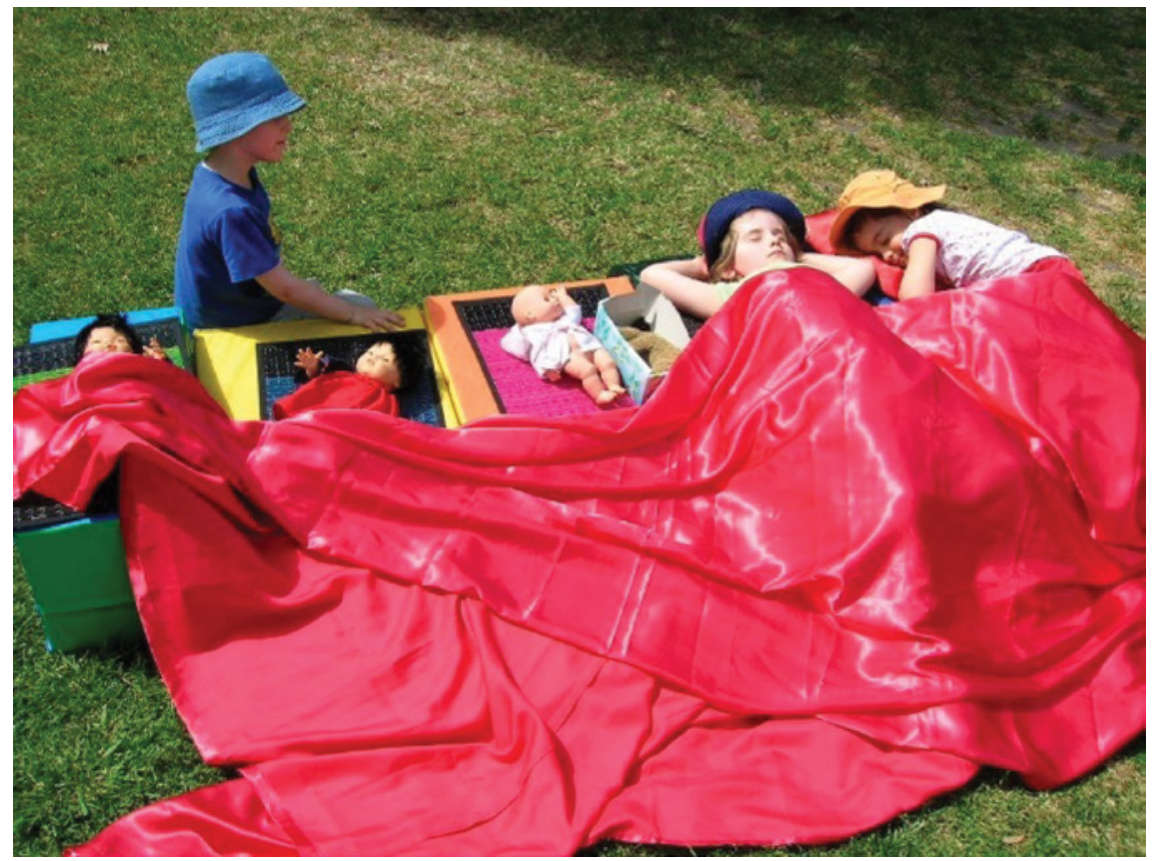

FIGURE 5 "Guests from China have arrived". Quentin is the dad, putting babies to sleep, as they had to "change their beds" due to "more people in the house". Claire - the mum - is asleep

were not only among the children but also between the children and the musician. More outgoing children, like Claire and Elan, established contact immediately, while others took longer. With increased group support and familiarity, the children's confidence was elevated which was also reflected in heightened levels of active participation. Participating in the program and receiving positive feedback made the children feel positive about themselves, which has been associated with effective learning (Lee \& Carr, 2012). By means of singing songs in different languages, they also became more interested in cultural similarities and differences. This would have not been possible if the children were not given time to play and form relationships on their own terms. Allowing for this 'free time' was crucial to the success of this music project and it was necessary to 'see' children at play; otherwise, group sessions on their own would have been limiting and focused on reproduction of the repertoire. Play episodes, such as Claire's invented song - a common feature of young children's early musical engagement (Berrett, 2006) - would have been missed if close observations were not conducted, shared, and celebrated with the partakers of this project. 
This paper illustrates how adopting a socio-cultural perspective in research, in the form of Learning Stories approach, presents us with a rich image of a childa proactive participant that shapes her own and the learning of others. The naturalistic, organic, yet methodical nature of the Learning Stories provided vivid evidence of children's learning endeavours. The general approach of building partnerships with children and incorporating their active input has clearly enhanced this study. The children were enthusiastic contributors that took ownership of the musical materials, adopting the musical content into their spontaneous musical play (e.g. Elan singing songs learned during the sessions at other times during the week, or Claire creating her own 'Italian'). The Learning Stories approach facilitated collaboration and two way communication: letting the children see what is recorded and giving them an active role in the generation and selection of data. For example, the children were invited to choose the photos they liked and place them in the data pool for interpretation. Treating the children as collaborators required respect for their interests and preferences. This meant that the musician/researcher strove to adapt and design the music program delivery according to the children's experiences of learning through spontaneous play.

This paper brings about awareness that everyday play and interactions among children are fertile ground for the progression of musical knowledge and conventions. As they are constructing musical cultural conventions, children gradually build up a stock of shared customs and actions that are understood by all group members (Marsh, 2008). Small and regular group times and peer learning strengthen the group cohesion and can bring about new friendships, which can then be elevated in children's spontaneous play. The project sheds more insight into young children's responses to culturally diverse songs, but it also exemplifies the fruitful effects of balanced programs that offer space for children's ownership of play and learning. The strong socio-cultural associations of music and especially song made it an ideal medium to combine pedagogies of music and diversity.

As mentioned earlier, most scholars regard play as a main vehicle for learning. Through play children realise their considerable and multifaceted capacity to wonder, experiment, problem-solve, investigate, negotiate, contemplate, create and re-create, and do this on their own terms. In this study, play was necessary to allow children to test their ideas and instinctively seek meaning, building on previous experiences and social interactions(Vygotsky, 1978).Toachievefullfillment and experience enjoyment, theseyounglearnersneeded to be instrincticallymotivated; such incentive is found in play. As endorsed by literature (Young, 2018), 
children's musical play observed in this study was rich and multimodal - visual, kinaesthetic, aural; child-centred, child-structured, child-motivated, and childrun. The spontaneous musical play was a social conjunction of ideas and musicking where vocalising, improvising with instruments, musical conversation, listening etc. were initiated by the children. That music was embraced by the children was not a surprise. Children enjoy musicking, especially singing, and are highlymotivated when it comes to trying out new songs(Nyland etal., 2015). They benefit from the development of their musical skills as well as from a broadening of their awareness of diversity (Rogoff, 2003). Experts agree that some form of musical receptiveness is innate to all children (Young, 2018), so the positive effects of exposure to music and nurturing of musical play could potentially be achieved for all children. Surrounded by sound and music, children generally respond to it with interest and excitement. Educators have a responsibility to help children discover how to listen to the world around them in a conscious way and how to use sound and music as a means of expressing this understanding of the world (Nyland et al., 2015). Continuing to encourage children to communicate their musical inclinations while simultaneously familiarising them with new and different resources and ideas can provide us with a deeper understanding of the complexities and ongoing importance of music and diversity in the lives of young children. This research used a socio-cultural (Learning Stories) approach; however, Young reminds us, there is not, nor should be, one way of sharing music, since, "every research inevitably adopts a particular theoretical perspective which is partial - illuminating some aspects and occluding others". She further warns us to "... be aware of the theoretical choices and the consequences of those choices, to be aware of whose voices are heard and whose voices not heard, which children stand to gain and which, importantly, may lose out" (2016, p.8).

This was a naturalistic case study with qualitative methodology founded on Vygotskian concepts of enculturation through relationships in context, engagement and participation. The music program was conducted playfully, concentrating not only on the musical features and premeditated pedagogical devices, but on children's contribution to the content and arrangements of the music sessions. Opportunities for spontaneous play with the resources from the music sessions were pivotal to this project and this consideration is strongly recommended for future research projects.

\section{References}

Acker, A. \& Nyland, B. (2017). Music as a Platform for Intercultural Understanding: Early childhood curriculum and a growing neoliberal imperative. In C. Roofe \& 
C. Bezzina (Eds.), Intercultural Studies of Curriculum Theory, Policy and Practice (pp. 85-104). Springer.

Campbell, P. S., \& Wiggins, T. (Eds.). (2013). The Oxford handbook of children's musical cultures. Oxford University Press.

Carr, M. (2001). Assessment in Early Childhood Settings: Learning Stories. Paul Chapman Publishing.

Carr, M., \& Lee, W. (2012). Learning Stories: Constructing learner identities in early education. Sage.

Hendricks, B. (2011). Designing for Play. Ashgate Publishing.

Marsh, K. (2008). The Musical Playground: Global tradition and change in children's songs and games. Oxford University Press.

McMillan, J. H., \& Schumacher, S. (2010). Research in Education (7th ed.). Pearson Education.

Niland, A. (2009). The Power of Musical Play: the value of play-based, child-centred curriculum in early childhood music education. General Music Today, 23(1), 17-21.

Nyland, B., \& Acker, A. (2012). Young Children's Musical Explorations: The potential of using learning stories for recording, planning and assessing musical experiences in a preschool setting. International Journal of Music Education, 3o(4), 328-340.

Nyland, B., Acker, A., Ferris, J., \& Deans, J. (2015). Musical Childhoods: Explorationsin the pre-schoolyears. Routledge.

Rogoff, B. (2003). The Role of Culture in Development. Cambridge University Press.

Vygotsky, L. S. (1978). Mind in Society. Cambridge University Press.

Young, S. (2016). Early Childhood Music Education Research: An overview. Research Studies in Music Education, 38(1), 9-21.

Young, S. (2018). Critical New Perspectives on Early Childhood Music: Young children engaging and learning through music. Routledge. 